Dhaka Univ. J. Biol. Sci. 21(1): 87-96, 2012 (January)

\title{
EFFECT OF ARSENIC ON THE NUTRIENT UPTAKE PATTERN OF AMARANTHUS
}

\author{
Sajal Roy, ZaKia ParveEn ANd S. M. IMAmul HuQ* \\ Bangladesh-Australia Centre for Environmental Research, Department of Soil, Water and \\ Environment, University of Dhaka, Dhaka-1000, Bangladesh.
}

Key words: Amaranthus, Arsenic, Effect, Nutrient uptake

\begin{abstract}
A macrocosm study was carried out to assess the transfer of arsenic (As) from irrigation water and sludge of arsenic removal water filter to two varieties of Amaranthus and their effects on phosphorus (P), potassium (K), sulfur $(\mathrm{S})$, calcium $(\mathrm{Ca})$ and magnesium $(\mathrm{Mg})$ uptake. $\mathrm{P}$ and $\mathrm{K}$ uptake in shoot and root were negatively affected by As that were not significant. However, a significant negative relationship was observed between As and $\mathrm{S}$ in shoot. A positive and significant relationship existed between As and Ca of green Amaranthus shoot but it was negative and insignificant in case of red Amaranthus. $\mathrm{Mg}$ content of shoot and root was positively affected by As in green Amaranthus. On the other hand, in the red Amaranthus the relation between As and $\mathrm{Mg}$ was positive in the shoot but negative in the root.
\end{abstract}

\section{Introduction}

Arsenic is a highly toxic element and its presence in food composites is a matter of concern to the well-being of both humans and animals. Recent reports have shown that some of our foodstuffs are contaminated with arsenic(1-2). It might be due to a high concentration of As in the soil where these foodstuffs are grown. Bangladesh economy is primarily based on agriculture. So, widespread uses of ground water for irrigation suggested that ingestion of irrigated crops and vegetables could be a major exposure route for $\mathrm{As}^{(3)}$. The uptake and accumulation of As by cereals, pulses and vegetable crops resulting in considerable reduction in the yields has been very well documented. Arsenic significantly decreases the biomass of winter wheat shoots and roots and significantly increases the concentrations of total $\mathrm{Mg}$ and $\mathrm{Ca}$ in shoots and enhances the transport of $\mathrm{Mg}$ and Ca from roots to shoots but decreases $\mathrm{K}, \mathrm{N}$ and $\mathrm{P}$ concentrations in both shoots and $\operatorname{roots}^{(4)}$.

Bangladeshi people consume mainly rice and vegetables. A wide variety of vegetables are available in Bangladesh. Most of the vegetables that need supplemental irrigation, and if the irrigation water is arsenic contaminated, it is likely that the vegetables will contain high amount of $\operatorname{arsenic}^{(5)}$. The serious As contamination in ground water leads to an accumulation of As in top soil which ultimately leads to As

*Corresponding author. <imamhuq@hotmail.com>. 
uptake by crops. At present, the disposal of the sludges from As filter media has become a great concern for the environmental, as well as plant and soil scientists. Once the sludges are disposed of into the soil, it would come into chemical reaction in soil at a certain time and there is a possibility of soil contamination with the toxic elements and it is likely that the element will end up in the growing plants ${ }^{(6)}$. Any adverse effect in the uptake of nutrients by plants due to As from contaminated ground water and disposed sludge is, therefore, important to ascertain.

\section{Materials and Methods}

The experiment was conducted in a macrocosm in the Department of Soil, Water and Environment, University of Dhaka.

Soil samples were collected from Dhamrai (Thana - Dhamrai, Village - Basna, Mouja - Sanora, District - Dhaka) which belongs to Dhamrai soil series. The geographic location of the sampling site is $23056.75 \mathrm{~N}$ and $90^{\circ} 07.746 \mathrm{E}$.

The bulk of soil samples representing 0 - $15 \mathrm{~cm}$ depth from the surface were collected by composite soil sampling method as suggested by the Soil Survey Staff of the USDA (7). The collected soil samples were dried in air for 5 days $\left(\sim 30^{\circ} \mathrm{C}\right)$. Visible roots and debris were removed from the soil samples and discarded. The larger and massive aggregates were broken down by gently crushing them using a wooden hammer and mixed thoroughly for making the composite. The bulk soil samples collected for pot experiment were screened through a $5 \mathrm{~mm}$ sieve. Two $\mathrm{mm}$ sieved soil samples were used for various physical analyses and $0.5 \mathrm{~mm}$ sieved soils were used for chemical and physicochemical analyses.

For the pot culture experiment, two leafy-vegetables commonly known as green Amaranthus (Data shak), and red Amaranthus (Lal shak) were used. All pot cultures were carried out in the three categories of soils viz., control, soil spiked with arsenic filter sludge (two sludges viz., granular ferric hydroxide and activated alumina were used as a source of As. A mixture of 50\% granular ferric hydroxide and $50 \%$ activated alumina at a rate of 1 ton/ha was used for this purpose), and irrigated soil with As salt (As was applied with irrigation water by dissolving As salt. The sources of As salt were sodium arsenate and sodium arsenite. A mixture of $80 \%$ sodium asenite and $20 \%$ sodium arsenate was used for this purpose. In this case As was applied at a rate of $1 \mathrm{mg} / \mathrm{l}$ ).

Pots of $5 \mathrm{~kg}$ sizes were taken having no holes in the bottom and marked in accordance with soil, plant and replication number. Then $4 \mathrm{~kg}$ of $5 \mathrm{~mm}$ sieved soil samples were taken in each of the earthen pots. The fertilizer requirement was assessed following Fertilizer Recommendation Guide by BARC ${ }^{(8)}$. The soil in each pot was mixed with the required amounts of urea, muriate of potash (MP) and triple super phosphate (TSP). The pots were arranged in a completely randomized design and were set in the net 
house (the macrocosm) of the department of Soil Water and Environment, University of Dhaka.

Seeds of green and red Amaranthus were collected from local market. Seeds (20 - 25) were sown in each of the pots on February 10, 2010 and allowed to germinate. After germination, 10 seedlings were kept in each pot.

Plants received watering every day. Tap water was used for control and arsenic spiked pots. In case of arsenic containing irrigated pots, a measured amount of water containing a definite concentration of As was applied. The amount of irrigation water was noted. From the total amount of water added, the content of total As applied was calculated. Intercultural operations were carried out whenever necessary.

The plants were harvested manually by uprooting them after 35 days of emergence. The roots of the harvested plants were washed first with tap water and then again with deionized distilled water. The plant samples were separated into two parts - roots and edible one. The fresh weights of the collected plant samples were taken. The samples were first air-dried and then oven-dried at $70 \pm 5^{\circ} \mathrm{C}$ for $48 \mathrm{hrs}$ and the dry weight of the plant samples were used for chemical analyses. The samples were ground with an electrical grinder and sieved through a $0.2 \mathrm{~mm}$ sieve.

Various physical, chemical and physico-chemical properties of the soil samples were analyzed in the laboratory as described in Huq and Alam ${ }^{(9)}$. For the determination of total As, $\mathrm{P}, \mathrm{K}, \mathrm{S}, \mathrm{Ca}$ and $\mathrm{Mg}$ the soil samples were digested with aqua regia $\left(\mathrm{HNO}_{3}: \mathrm{HCl}\right.$ $=1: 3$ ). The plant samples were digested with $\mathrm{HNO}_{3}$. The total nitrogen in soil and plant samples was determined by Kjeldahl's method following $\mathrm{H}_{2} \mathrm{SO}_{4}$ digestion. The total $\mathrm{P}$ was determined colorimetrically using a spectrophotometer at $490 \mathrm{~nm}$ by developing yellow color with vanadomolybdate. The available phosphorus of the soil was determined calorimetrically following the blue color method using ascorbic acid at wavelength of $880 \mathrm{~nm}$ after extracting by using the Bray \& Kurtz solution. The available and total $\mathrm{K}$ was determined by flame analyzer. The available potassium of the soils was extracted with $1 \mathrm{~N}$ ammonium acetate at $\mathrm{pH}$ 7. The total $\mathrm{S}$ was determined by turbidimetry using Tween-80. The total arsenic in soil and plant was determined by a hydride generation-atomic absorption spectrometer (HG-AAS)(10). All elements of plant samples were calculated on oven dry basis.

All data in the present experiment were statistically analyzed by using Microsoft Excel and MINITAB (version 13) Packages.

\section{Results and Discussion}

The collected soil samples were analyzed in the laboratory before setting up of the experiment to find out the nutrient status of the soil. Some important chemical properties of sludge were also determined. The contents of available N, P and K were found to be 
very low. Total N, P, K and S of the soil were also determined. The concentration of As in soil was not much high but sludge contained much higher concentration of As compared to soil. The experimental soil was loam in texture, acidic in reaction ( $\mathrm{pH}$ 5.4). The soil contained less than $0.591 \%$ organic matter. Important chemical properties are furnished as organic carbon $0.46 \%$, total $\mathrm{N} 0.102 \%$, total $\mathrm{P}-0.089 \%$, total $\mathrm{K} 0.346 \%$, total S $0.090 \%$, available N $61.11 \mathrm{mg} / \mathrm{kg}$, available P $4.187 \mathrm{mg} / \mathrm{kg}$, available K $11.76 \mathrm{mg} / \mathrm{kg}$, aqua regia extractable As $2.79 \mathrm{mg} / \mathrm{kg}$. Sludge contained $311.75 \mathrm{mg} / \mathrm{kg}$ As and $13.11 \% \mathrm{Fe}$.

The mean height and amount of fresh matter of green and red Amaranthus are given in Table 1. Plant height of red Amaranthus was found to be higher than green Amaranthus. A significant difference was found in plant height between two varieties giving $\mathrm{p}$ value of 0.038. In case of green Amaranthus, the treatment effects did not vary but in case of red Amaranthus, a significant difference ( $\mathrm{p}$ value 0.007) was found among treatments in relation to plant height. A highly significant difference was found among treatments in relation to fresh matter of both green Amaranthus ( $\mathrm{p}$ value 0.00) and red Amaranthus ( $\mathrm{p}$ value 0.00). Similar findings were reported where fresh yield of red Amaranthus decreased with the increase of As level(11).

Table 1. Height (cm) and fresh matter (gm) of shoot of green and red Amaranthus.

\begin{tabular}{lccccc}
\hline \multirow{2}{*}{ Treatments } & \multicolumn{2}{c}{ Green Amaranthus } & & \multicolumn{2}{c}{ Red Amaranthus } \\
\cline { 2 - 3 } \cline { 5 - 6 } & Height & Fresh weight & & Height & Fresh weight \\
\hline Control & 14 & $26.02^{\mathrm{a}}$ & & $18^{\mathrm{a}}$ & $37.98^{\mathrm{a}}$ \\
Spiked & 15 & $27.42^{\mathrm{a}}$ & & $19^{\mathrm{a}}$ & $39.3^{\mathrm{a}}$ \\
Irrigated & 12 & $20.63^{\mathrm{b}}$ & & $15^{\mathrm{b}}$ & $31.53^{\mathrm{b}}$ \\
\hline
\end{tabular}

Means followed by the same letter(s) in a column do not differ significantly from each other at $5 \%$ level of significance.

The mean values of arsenic content in shoot and root of green and red Amaranthus plants are presented in Table 2. Arsenic accumulation increased in arsenic treated plant samples compared to control. The total uptake (calculated by multiplying the concentration with the total dry matter produced) of arsenic by green Amaranthus was found to be $0.45,0.57$ and $6.38 \mathrm{mg} / \mathrm{kg}$ in control, As spiked and irrigated plant samples, respectively. The total uptake of As by red Amaranthus was 0.90, 2.7 and $8.63 \mathrm{mg} / \mathrm{kg}$ in control, As spiked and irrigated plant samples, respectively. As concentrations were higher in roots than in shoots.

Concentration and accumulation of As increased significantly both in shoot and root due to As treatments as compared to the control indicating that the bioavailability of arsenic depends on the concentration of As in the rooting medium and the higher the concentration the higher is the bioavailability. There was a trend that As concentration in roots was higher than that of shoots. The roots of vegetables and rice plants were found 
to accumulate highest amount of As compared to other parts of plants( ${ }^{(6)}$. Abedin et al.(12) also reported higher concentrations of As in roots of rice plants than the other parts.

Table 2. Concentration of Arsenic (mg/kg) in shoot and root of green and red Amaranthus.

\begin{tabular}{llllll}
\hline \multirow{2}{*}{ Treatments } & \multicolumn{2}{c}{ Green Amaranthus } & & \multicolumn{2}{c}{ Red Amaranthus } \\
\cline { 2 - 3 } \cline { 5 - 6 } & Shoot & Root & & Shoot & Root \\
\hline Control & $0.056^{\mathrm{b}}$ & $0.396^{\mathrm{b}}$ & & $0.115^{\mathrm{b}}$ & $0.788^{\mathrm{c}}$ \\
Spiked & $0.113^{\mathrm{b}}$ & $0.458^{\mathrm{b}}$ & & $0.18^{\mathrm{b}}$ & $2.523^{\mathrm{b}}$ \\
Irrigated & $0.784^{\mathrm{a}}$ & $5.594^{\mathrm{a}}$ & & $0.803^{\mathrm{a}}$ & $7.832^{\mathrm{a}}$ \\
\hline
\end{tabular}

Means followed by the same letter(s) in a column do not differ significantly from each other at $5 \%$ level of significance.

The contents of N, P, K, S, Ca and Mg in shoot and root of green and red Amaranthus are shown in Tables 3 and 4 . The contents of $P$ and $K$ in shoot and root of both green and red Amaranthus were found to be highest in As spiked plant samples. In green Amaranthus, the maximum accumulation of $\mathrm{S}$ was found in shoot of As spiked plants, whereas in red Amaranthus, the maximum accumulation was found in shoot and root of control plant samples. Ca and Mg contents in shoot of green Amaranthus were found to be highest in irrigated plant samples. In case of red Amaranthus, control plant samples showed maximum accumulation of $\mathrm{Ca}$ and irrigated plant samples showed maximum accumulation of $\mathrm{Mg}$ though a little difference was found between control and irrigated plant samples.

Table 3. Concentration of N, P, K, S, Ca and $\mathrm{Mg}$ in shoot and root of green Amaranthus.

\begin{tabular}{|c|c|c|c|c|c|c|c|c|c|c|c|}
\hline \multirow{2}{*}{ Treatments } & \multirow{2}{*}{$\frac{N(\%)}{\text { Shoot }}$} & \multicolumn{2}{|c|}{$\mathrm{P}(\%)$} & \multicolumn{2}{|c|}{$\mathrm{K}(\%)$} & \multicolumn{2}{|c|}{$\mathrm{S}(\%)$} & \multicolumn{2}{|c|}{$\mathrm{Ca}(\%)$} & \multicolumn{2}{|c|}{$\operatorname{Mg}(\%)$} \\
\hline & & Shoot & $\overline{\text { Root }}$ & Shoot & $\overline{\text { Root }}$ & Shoot & $\overline{\text { Root }}$ & Shoot & Root & Shoot & Root \\
\hline Control & 3.27 & 0.3 & 0.25 & 4.46 & 3.75 & $0.86^{\mathrm{ab}}$ & $0.85^{\mathrm{a}}$ & $1.45^{\mathrm{b}}$ & $0.72^{\mathrm{a}}$ & 1.9 & 0.31 \\
\hline Spiked & 3.52 & 0.4 & 0.34 & 4.72 & 3.94 & $1.05^{\mathrm{a}}$ & $0.81^{a}$ & $1.43^{\mathrm{b}}$ & $0.56^{\mathrm{ab}}$ & 1.6 & 0.27 \\
\hline Irrigated & 3.82 & 0.3 & 0.31 & 4.21 & 3.21 & $0.60^{\mathrm{b}}$ & $0.59^{\mathrm{b}}$ & $1.85^{\mathrm{a}}$ & $0.45^{\mathrm{b}}$ & 2.08 & 0.4 \\
\hline
\end{tabular}

Means followed by the same letter(s) in a column do not differ significantly from each other at $5 \%$ level of significance.

Table 4. Concentration of N, P, K, S, Ca and $\mathrm{Mg}$ in shoot and root of red Amaranthus.

\begin{tabular}{|c|c|c|c|c|c|c|c|c|c|c|c|}
\hline \multirow{2}{*}{ Treatments } & \multirow{2}{*}{$\begin{array}{l}\mathrm{N}(\%) \\
\text { Shoot }\end{array}$} & \multicolumn{2}{|c|}{$\mathrm{P}(\%)$} & \multicolumn{2}{|c|}{$\mathrm{K}(\%)$} & \multicolumn{2}{|c|}{ S (\%) } & \multicolumn{2}{|c|}{$\mathrm{Ca}(\%)$} & \multicolumn{2}{|c|}{$\operatorname{Mg}(\%)$} \\
\hline & & Shoot & Root & Shoot & Root & Shoot & Root & Shoot & Root & Shoot & Root \\
\hline Control & 3.58 & $0.39^{b}$ & 0.24 & $5.64^{\mathrm{ab}}$ & 4.77 & $0.76^{\mathrm{a}}$ & 0.9 & 1.07 & 0.7 & 1.56 & $0.60^{\mathrm{a}}$ \\
\hline Spiked & 3.8 & $0.48^{a}$ & 0.29 & $6.03^{a}$ & 5.14 & $0.54^{\mathrm{b}}$ & 0.7 & 0.87 & 0.68 & 1.3 & $0.80^{\mathrm{a}}$ \\
\hline Irrigated & 3.49 & $0.41^{\mathrm{b}}$ & 0.26 & $5.12^{\mathrm{b}}$ & 4.46 & $0.45^{\mathrm{b}}$ & 0.74 & 0.93 & 0.49 & 1.58 & $0.25^{\mathrm{b}}$ \\
\hline
\end{tabular}

Means followed by the same letter(s) in a column do not differ significantly from each other at $5 \%$ level of significance. 
The effect of As on P content is presented in the Fig. 1. The relationship between As and $\mathrm{P}$ in shoot was found to be negative both for green and red Amaranthus the values being insignificant ( $\mathrm{p}$ value 0.608 and 0.671 , respectively). The root arsenic and root $\mathrm{P}$ of red Amaranthus also showed insignificant negative correlation the $\mathrm{p}$ value being 0.987 . Reduction of $\mathrm{P}$ concentrations may be due to the fact that the arsenate is taken up by the phosphate transport system ${ }^{(13)}$ and decreasing both $\mathrm{P}$ concentration and $\mathrm{P}$ accumulation. However, the relationship between As and P in the roots of green Amaranthus was found to be positive but insignificant ( $\mathrm{p}$ value 0.641 ).
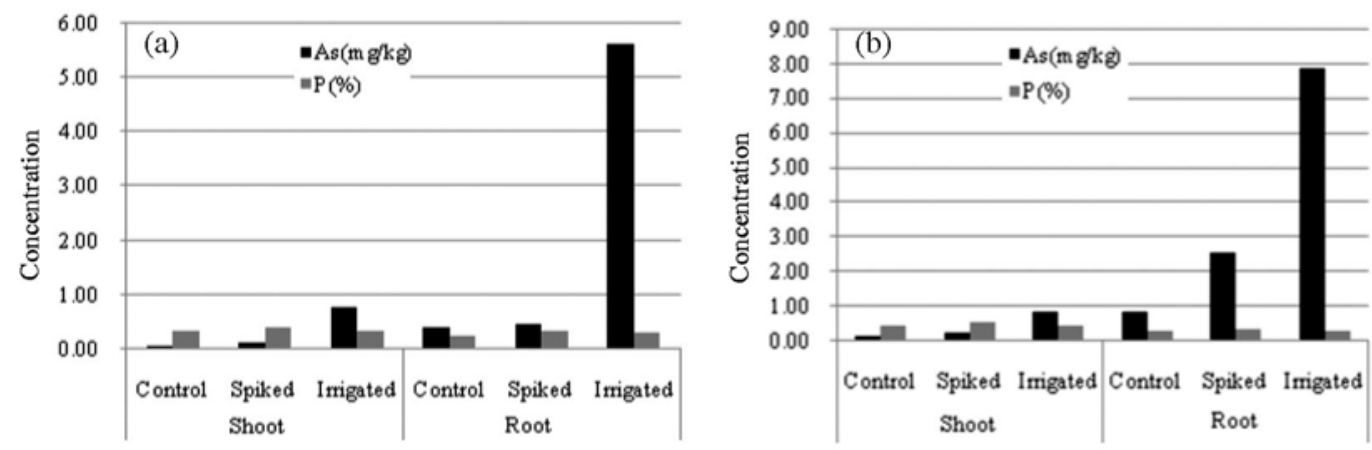

Fig. 1. Effect of As (mg/kg) on P (\%) content in shoot and root of (a) green Amaranthus and (b) red Amaranthus.

The effect of As on $\mathrm{K}$ content is shown in the Fig. 2. As had a negative and insignificant effect on the uptake of $K$ in shoot ( $p$ value 0.545 ) and root ( $p$ value 0.305 ) of green Amaranthus. In case of red Amaranthus, the relationship between As and $\mathrm{K}$ was also found to be negative and insignificant both for shoot ( $p$ value 0.079 ) and root ( $p$ value $0.409)$.
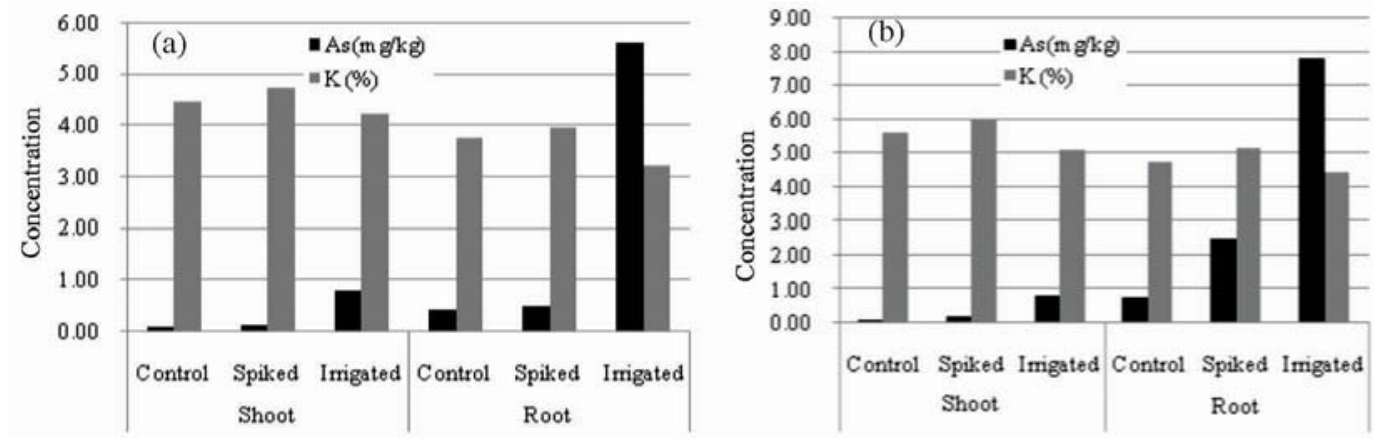

Fig. 2. Effect of As (mg/kg) on K (\%) content in shoot and root of (a) green Amaranthus and (b) red Amaranthus.

Arsenic decreased the accumulation of $\mathrm{K}$ both in shoots and roots which is in agreement with the result of Wallace et al.(14), who showed that depression of $\mathrm{K}$ concentration in roots of bush bean plants was due to arsenic in the nutrient solution. 
A significant negative relationship was found between As and $S$ in shoot of both green Amaranthus ( $\mathrm{p}$ value 0.049) and red Amaranthus ( $\mathrm{p}$ value 0.05). Although As had significant negative effect on the concentration of $S$ in root (P value 0.012) of green Amaranthus, the effect of As on S in root of red Amaranthus was found to be negative but insignificant ( $\mathrm{p}$ value 0.625 ). Merry et al. ${ }^{(15)}$ reported the interaction between sulfur and As. They pointed out that $S$ and As exists in soil solution in similar ionic forms (e.g. sulfate and arsenate) and there should be a competition between these two ions. The effect of As on the content of $S$ is shown in the Fig. 3.
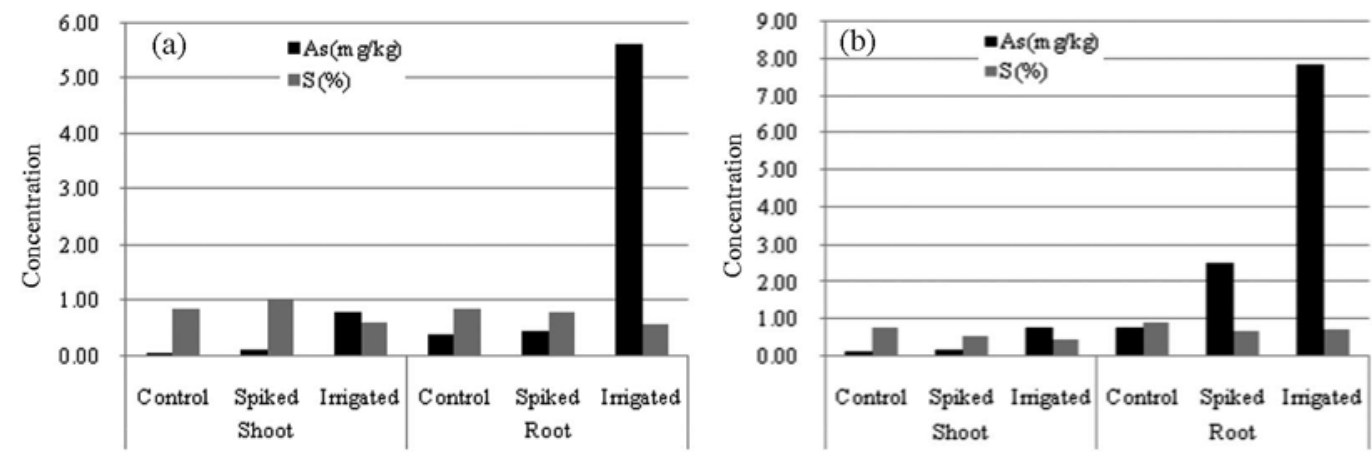

Fig. 3. Effect of As (mg/kg) on S (\%) content in shoot and root of (a) green Amaranthus and (b) red Amaranthus.

The effect of As on Ca content is shown in Fig. 4. In case of green Amaranthus, a positive correlation was found between arsenic and calcium in shoot that was significant ( $\mathrm{p}$ value 0.002). But the relationship between As and $\mathrm{Ca}$ was negative and significant ( $\mathrm{p}$ value 0.026) for root. A negative but insignificant relation between As and Ca was found both for shoot ( $p$ value 0.668 ) and root ( $p$ value 0.234 ) of red Amaranthus.
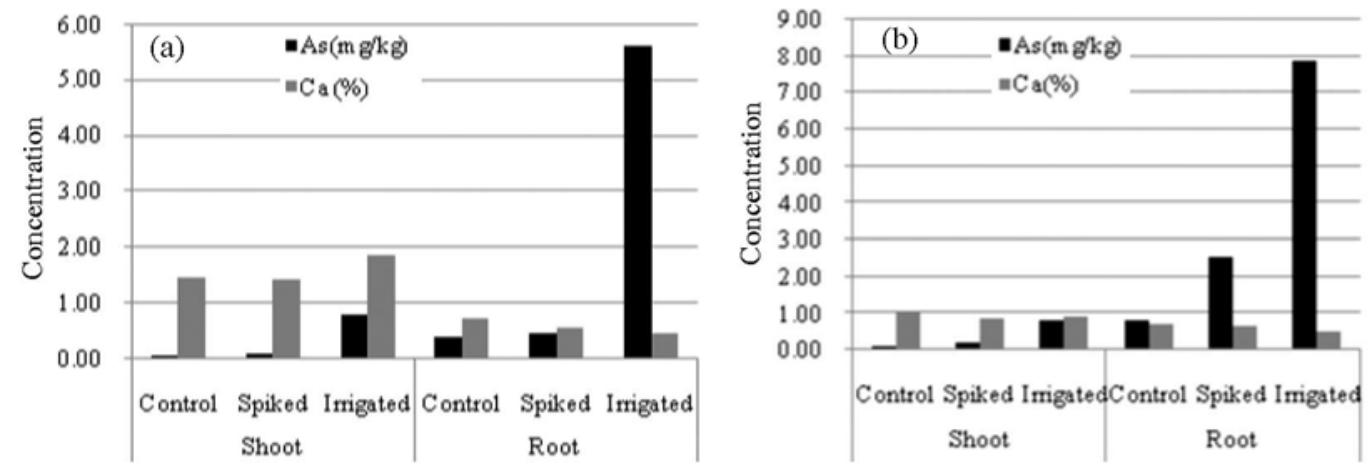

Fig. 4. Effect of As (mg/kg) on Ca (\%) content in shoot and root of (a) green Amaranthus and (b) red Amaranthus.

The decrease in Ca content in As treated plants is in agreement with the result of Wallace et al.(14) who showed the depression of Ca concentration in leaves and roots of bush bean plants was due to As-toxicity. However, the significant increase in the 
concentration of $\mathrm{Ca}$ in shoot of green Amaranthus could be due to some metabolic aberrations where Ca-pectate formation has been increased because of higher arsenic toxicity on green Amaranthus.

The effect of As on the content of $\mathrm{Mg}$ is shown in Fig. 5. A positive relationship was found between As and $\mathrm{Mg}$ in the shoots of both green Amaranthus ( $\mathrm{p}$ value 0.186) and red Amaranthus ( $\mathrm{p}$ value 0.946). The relationship between $\mathrm{As}$ and $\mathrm{Mg}$ in root of green Amaranthus was also positive and insignificant ( $\mathrm{p}$ value 0.178). Carbonell-Barrachina et al. ${ }^{(16)}$ have shown similar result in stems of bean plants at harvesting stage when sodium arsenite was applied at $5 \mathrm{mg}$ As/l. But the relationship between As and $\mathrm{Mg}$ in root of red Amaranthus was found negative. Shaibur ${ }^{(17)}$ found a significant negative effect on the concentration of $\mathrm{Mg}$ both in shoots and roots of barley plants due to As treatments.
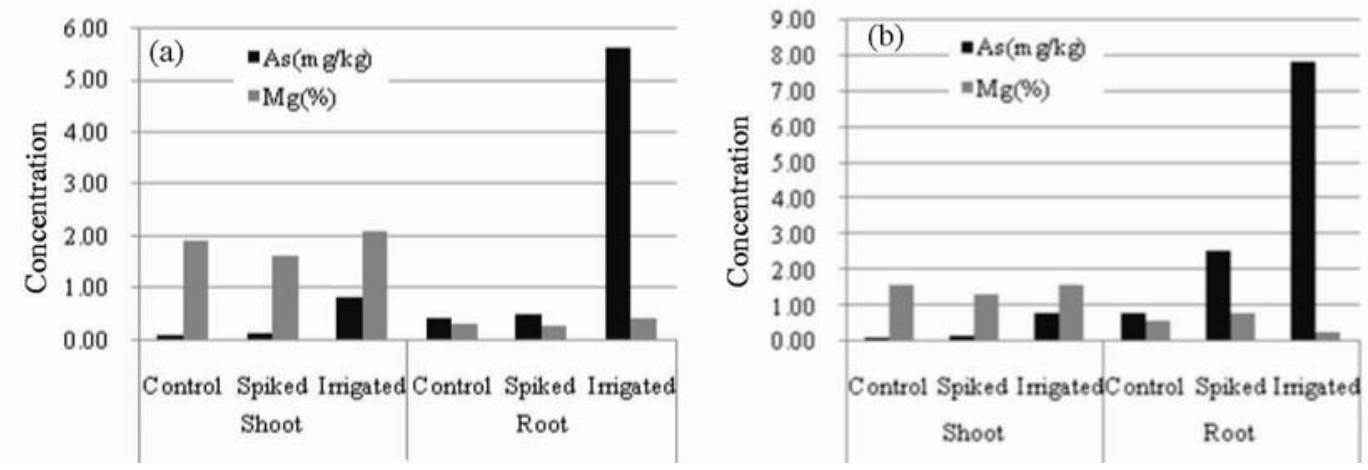

Fig. 5. Effect of As (mg/kg) on $\mathrm{Mg}(\%)$ content in shoot and root of (a) green Amaranthus and (b) red Amaranthus.

It could be concluded from the present observations that As in the growth medium of Amaranthus, a very common and popular leafy vegetable, could differently affect the mineral nutrition of the plant. However, the varietal difference of the vegetable has influence on the effect of As in the mineral nutrition.

\section{References}

1. Huq SMI and R Naidu 2003. Arsenic in ground water of Bangladesh: Contamination in the food chain. In: Arsenic Contamination: Bangladesh Perspective (Ahmed MF Ed.). ITNBangladesh, Centre for water supply and waste management. BUET, Dhaka, Bangladesh. pp. 203-226.

2. Meharg AA and MM Rahman 2003. Arsenic contamination of Bangladesh paddy field soils: Implications for rice contribution to arsenic consumption. Environ. Sci. Technol. 37: 22934.

3. WHO (World Health Organization) 2001. Arsenic and arsenic compounds. Environmental Health Criteria (2nd ed), Geneva, World Health Organization. p. 22. 
4. Lui Q, C Hu, Q Tan, X Sun, J Su and Y Liang 2008. Effects of As on As uptake, speciation, and nutrient uptake by winter wheat (Triticum aestivum L.) under hydroponic conditions. J. Environ. Sci. 20(3): 326-331.

5. Huq SMI, JC Joardar, S Parvin, R Correll and R Naidu 2006. Arsenic contamination in food chain: Arsenic transfer into food materials through groundwater irrigation. J. Health Popul. Nutr. 24(3): 305-316.

6. Huq SMI, L Nesa, MTA Chowdhury and JC Joardar 2011. Disposal of arsenic filter sludge in soil and its consequences. Environ. Sci. Eng. 5(2): 165-176.

7. USDA (United States Department of Agriculture) 1951. Soil Survey Manual. Soil Survey Staff, Bureau of Plant Industry, Soils and Agricultural Engineering, United States Department of Agriculture, Washington. Handbook 18. p. 205.

8. BARC (Bangladesh Agricultural Research Council) 2005. Fertilizer Recommendation Guide 2005. (Miah MMU, ATM Farid, MAM Miah, M Jahiruddin, SMK Rahman, MA Quayyum, MA Sattar, MA Motalib, MF Islam, M Ahsan, S Razia Eds). BARC, Dhaka, Bangladesh. pp. $119-245$.

9. Huq SMI and MD Alam 2005. A Handbook on Analyses of Soil, Plant, and Water. BACER-DU, University of Dhaka, Bangladesh. pp. 1-246.

10. Portman JE and JP Riley 1964. Determination of arsenic in seawater, marine plants and silicate and carbonate sediments. Anal. Chem. Acta. 31: 509-519.

11. Choudhury MRQ, ST Islam, R Alam, I Ahmad, W Zamam, R Sen and MN Alam 2008. Effects of Arsenic on Red Amaranth (Amaranthus retroflexus L.). Am-Euras. J. Sci. Res. 3(1): 48-53.

12. Abedin MJ, J Feldman and A Meharg 2002. Uptake kinetics of arsenic species in rice (Oryza sativa L.) plants. Plant Physiol. 128: 1120-1128.

13. Meharg AA and MR Macnair 1990. An altered phosphate uptake system in arsenate-tolerant Holcus lanatus L. New Phytol. 116: 29-35.

14. Wallace A, RT Mueller and RA Wood 1980. Arsenic phytotoxicity and interactions in bush bean plants grown in solution culture. Plant Nutri. 2: 111-113.

15. Merry RH, KG Tiller and AM Alsten 1986. The effect of contamination of soil with copper, lead and arsenic on the growth and composition of plants. Plant and Soil 91: 115-126.

16. Carbonell-Barrachina AA, F Burlo'-Carbonell and J Mataix-Beneyto 1997. Effect of sodium arsenite and sodium chloride on bean plant nutrition (macronutrients). Plant Nutri. 20:1617-1633.

17. Shaibur MR, N Kitajima, R Sugawara, T Kondo, SMI Huq and S Kawai 2008. Physiological and mineralogical properties of arsenic-induced chlorosis in barley seedlings grown hydroponically. Plant Nutri. 31: 333-353.

(Manuscript received on 1 October, 2011; revised on 15 October, 2011) 